\title{
ATIVIDADES INCLUSIVAS NAS AULAS DE EDUCAÇÃO FÍ́SICA: Atitudes de Estudantes sobre Inclusão
}

\section{INCLUSIVE ACTIVITIES IN PHYSICAL EDUCATION CLASSES: STUDENT ATTITUDES ON INCLUSION}

\section{Rafaela Dybas Voigt}

Secretaria de Estado da Educação do Paraná

Adriana Inês de Paula

Universidade Federal do Paraná (UFPR)

E-mail: dripaula9@hotmail.com

\section{INTRODUÇÃOO}

ada vez mais a luta pelos direitos humanos se fortalece e nessa luta
destacamos a inclusão escolar como relevante estratégia no intuito de acabar com as práticas discriminatórias, ao encontro de uma sociedade mais democrática e mais justa. A necessidade de atitudes e práticas inclusivas se estabelece para que haja a almejada igualdade de direitos para todas e todos (FREITAS, 2006).

Mantoan (2006) alerta que o ambiente escolar pode vir a ser um lugar de desenvolvimento de diversas e perversas maneiras de exclusão, de não aceitação e não acolhimento. Por outro lado, Hehir e Pascucci (2016) asseguram que estudar em ambientes que valorizam a diversidade humana, em que estão juntos estudantes com e sem deficiência, pode ter efeitos positivos nas atitudes e nas crenças sociais de todas e todos envolvidos no cenário educacional.

O ambiente inclusivo é capaz de promover diversos proveitos advindos da convivência entre pares com e sem deficiência estudando e realizando tarefas no mesmo espaço, com os mesmos objetivos. Hehir e Pascucci (2016) descrevem cinco desses benefícios: 
Redução do medo das diferenças humanas, acompanhada por um maior conforto e consciência (menos medo de pessoas com aparência ou comportamento diferentes); crescimento da cognição social (aumento da receptividade aos outros, comunicação mais eficaz com todos os colegas); melhorias no autoconceito (aumento da autoestima, do status percebido e da sensação de pertencimento); desenvolvimento de princípios morais e éticos pessoais (menos preconceito, maior capacidade de responder às necessidades dos outros); e amizades carinhosas (HEHIR; PASCUCCI, 2016, p. 12).

É fundamental preparar a escola para incluir qualquer estudante, a fim de que os benefícios sejam diversos para todas e todos envolvidas/os com a educação: alunas/os, professoras/es, coordenador/a, servidoras/es educacionais e a sociedade em geral. Esse preparo envolve sem dúvida a desconstrução de barreiras sejam elas visíveis ou invisíveis, físicas ou virtuais (FREITAS, 2006).

Entre as possíveis barreiras presentes no ambiente escolar estão as barreiras atitudinais, representadas por ações ou omissões preconceituosas contra as pessoas com deficiência ou grupos vulneráveis. Muitas vezes não são explícitas como as barreiras arquitetônicas, mas que impedem tanto quanto ou mais a plenitude de sucesso das vivências inclusivas.

A Educação Física escolar enquanto componente curricular, possibilita entre seu vasto escopo, vivências e experiências constantemente compartiIhada entre os pares. As práticas corporais vivenciadas na aula de educação física, em sua maioria das vezes, se dão na presença e no contato direto entre estudantes, produzindo então uma infinidade de possíveis interações, sensações, percepções, tomadas de decisões e atitudes frente aos diferentes colegas da aula.

Diante da diversidade cada vez mais presente e desejável e considerando seu relevante papel no processo educacional, não se pode mais pensar em uma única forma de educação física, mas numa educação física plural, que esteja atenta para as diferenças, identificando-as e reconhecendo-as. As diferenças devem ser incluídas, acolhidas, valorizadas, e jamais interpretadas como possibilidade de seleção, separação e hierarquização, como no passado (ARAÚJO, 2011).

Considerando que as barreiras atitudinais podem estar presentes nas interações entre todas/os participantes do ambiente escolar: professoras/es, 
servidoras/es, coordenadores/as e alunas/os e entendendo que tais barreiras, mesmo que sutilmente, podem atrapalhar a implementação e manutenção de uma perspectiva de educação física inclusiva, o objetivo desse trabalho foi avaliar o impacto da vivência de atividades físicas adaptadas, simulando deficiências sensoriais e motora, na compreensão e atitudes de alunas/os sem deficiência sobre o processo de inclusão.

\section{INCLUSÃO DAS PESSOAS COM DEFICIÊNCIA NA EDUCAÇ̃̃O FÍSICA ESCOLAR}

A Declaração de Salamanca é considerada um dos principais marcos existentes que visam a inclusão social. O documento foi elaborado e publicado em Salamanca, na Espanha em 1994, junto a Conferência Mundial sobre Educação Especial, com o objetivo de fornecer diretrizes básicas para direcionar reformas políticas e sistemas educacionais de acordo com o movimento de inclusão social. Mais de trinta países se comprometeram com essas diretrizes, sendo o Brasil um de seus signatários (SALAMANCA, 1994).

O documento ampliou o conceito de necessidades educacionais especiais, incluindo todas as crianças até então, excluídas dos benefícios propiciados pelo ambiente escolar. A Declaração evidencia o ambiente favorável que o paradigma inclusivo proporciona para o alcance da igualdade de oportunidades e de participação para as pessoas com deficiência, e seu sucesso depende do compromisso e engajamento de todas e todos envolvidas/os nesse processo, visando o aprendizado inclusivo e de qualidade através de um currículo apropriado (AWAD, 2010).

Segundo Freitas (2006, p. 167) sob a perspectiva inclusiva é possível detectar a inserção de um outro olhar, ou seja, uma maneira nova de se ver, ver os outros e ver a educação. Para incluir todas as pessoas, a sociedade deve ser modificada com base no entendimento de que é ela que precisa ser capaz de suprir às necessidades dos indivíduos. Sendo assim, inclusão se refere à modificação da sociedade como apoio para que pessoas com algum tipo de deficiência busquem seu desenvolvimento e exerçam sua cidadania.

É atribuída à escola, entre outras funções, a de preparar a/o aluna/o para o mundo e para as transformações da sociedade (ARAÚJO, 2011). Entre 
seus princípios fundamentais, no que diz respeito ao ensino inclusivo, Freitas (2006, p. 167) descreve que " todos os alunos, sempre que possível, devem aprender juntos, independentemente de suas dificuldades ou talentos, deficiências, origem socioeconômica ou cultural em escolas e salas de aula, provedoras, nas quais todas as necessidades são satisfeitas" e ainda, que o ensino inclusivo só é alcançado se todo corpo docente e todo recurso disponível estão aliados de forma única e consciente para esse fim.

O necessário compromisso com o sucesso da aprendizagem de todas/ os exige que o corpo docente (des)considere suas diferenças culturais, sociais e pessoais e, sob hipótese alguma, as reafirme como causa de desigualdade ou de exclusão (FREITAS, 2006, p. 179). Esse compromisso deve ultrapassar a barreira da dificuldade que comumente ouvimos em discursos de educadoras/es que atuam em ambientes inclusivos.

Mauerberg-deCastro e Castro (2011) descrevem a inclusão como uma proposta educacional que se esforça para alterar o ambiente em direção ao acolhimento de estudantes com deficiência, possibilitando suportes que garantam sua convivência e sua permanência nas escolas regulares de ensino. "A diferença é vista como vantagem, e deve ser resgatada sob a condição de mudanças atitudinais de todos os envolvidos" (MAUERBERG-DECASTRO; CASTRO, 2011, p. 504).

A educação física é fundamental, pois possibilita o processo educativo como um todo, sem dissociar corpo e mente. Ela é capaz de desenvolver e aprimorar as habilidades físicas, morais e sociais do grupo, pois inúmeras são as situações de tomadas de decisão que dependem das atitudes próprias e das/os outras/os estudantes. Se bem planejada e desenvolvida, é uma excelente ferramenta de inclusão (FERREIRA, 2010). Os Parâmetros Curriculares Nacionais, resgata educação física como a "educação física para todos", principalmente no que se refere a estudantes que apresentam necessidades diferenciadas, permanentes ou não.

A subdisciplina da Educação Física que debruça sobre as implicações da prática da atividade física para pessoas com deficiência é chamada de 'atividade física adaptada'. De acordo com Mauerberg-deCastro (2011, p. 16) tem como objetivo "integrar e aplicar fundamentos teórico-práticos de diferentes disciplinas da motricidade humana e das diversas áreas vizinhas da saúde e 
da educação" em diferentes implicações, sejam na área educacional, seja na reabilitação e/ou esportes. A autora ainda descreve que:

A atividade física adaptada é uma área profissional cuja prestação de serviços fundamenta-se num corpo de conhecimentos multi, inter e cross-disciplinares. É dirigido à identificação e à solução de problemas psicomotores, ao longo do período vital, os quais, de uma forma ou de outra, limitam a expressão potencial do indivíduo, comprometendo sua adaptação. Esses problemas podem ter origem intrínseca (no indivíduo em si) ou extrínseco (no ambiente), e só tornam visíveis, à medida que as demandas de tarefa, por causa de limitações ou de atrasos nas funções adaptativas não são satisfeitas (MAUERBERG-DECASTRO, 2011, p. 16).

Nesse sentido, é interesse de estudo dessa área as contribuições teórico e práticas frente ao processo de inclusão das pessoas com deficiência, sobretudo nas situações de práticas e vivências corporais como as que ocorrem nas aulas de educação física escolar. Portanto, é interesse do presente estudo analisar se um programa de intervenção composto de práticas de atividade física sob condição de simulação de deficiências, privação de visão, de audição e de mobilidade, são capazes de impactar na percepção e nas atitudes de estudantes sem deficiência frente a inclusão de estudantes com deficiências como pares.

\section{MÉTODO}

\section{Participantes}

Participaram do presente estudo 79 estudantes de 3 turmas de 5ㅇano de um colégio de ensino privado da cidade de Curitiba/PR, sendo 42 meninas e 37 meninos com faixa etária variando entre 9 e 11 anos. Apesar de ser uma escola inclusiva, as turmas que participaram do estudo não possuem estudantes com deficiência.

\section{Procedimentos}

Utilizamos no presente estudo a adaptação de um instrumento avaliativo elaborado por Mauerberg-de Castro (2011) que busca avaliar atitudes ou comportamentos afetivos ligados ao desenvolvimento moral e social, e 
que compreendeu a visão das/os participantes em relação às pessoas com deficiência em dois momentos distintos: antes e após um período de intervenção nas aulas de educação física em que as/os alunas/os participavam de atividades motoras sob condição de simulação de deficiências, sensoriais e motora, e finalizavam a aula com uma roda de conversa sobre a experiência realizada. A coleta de dados aconteceu ao longo de 1 mês entre as 3 turmas e a intervenção foi constituída de 5 partes:

1a - apresentação da experimentadora do estudo as/aos alunas/os, breve explicação sobre o estudo, leitura e aplicação do questionário (pré). Além disso, foram sanadas algumas dúvidas das/os alunas/os referentes ao estudo.

$2^{\text {a }}$ - aula prática com atividade que simulava a deficiência visual e feedback ao final da aula.

Atividade: Futmão vendado - participantes formaram um grande círculo, todas/ os estavam vendadas/os com fitas de TNT, com as pernas afastadas e principalmente em silêncio. O objetivo do jogo era rebater a bola (com guizo) com as mãos quando ouviram sua aproximação, de modo que a bola passasse entre as pernas da/o colega, protegendo as suas próprias pernas.

Objetivo: obstruir a visão das/os alunos para vivenciarem, de maneira simulada, a deficiência visual.

3ํㅡ - aula prática com atividade que simulava a deficiência auditiva e feedback ao final da aula.

Atividade: Coelho sai da toca - participantes foram divididos em coelhos e tocas. Ao sinal da experimentadora, mudaram de localização. Os gestos imitando coelhos indicavam que os coelhos deveriam mudar, enquanto que os gestos imitando toca determinava que as tocas mudariam de lugar. A/o aluna/o que sobrava, realizava o próximo gesto e voltava para a brincadeira.

Objetivo: Limitar os sons e a fala das/os alunas/os, valorizar os gestos e o contato visual de modo a vivenciarem, de maneira simulada, a deficiência auditiva.

40 - aula prática com atividade que simulava a deficiência motora e feedback ao final da aula.

Atividade: Passa bola com os pés - participantes foram divididas/os em duas equipes, sentadas/os no chão. A meta era passar a bola com os pés para a/o colega até chegar no último da fila que estava próximo ao gol, devendo jogar a bola no mesmo, sem utilizar os braços. Houve rodízio de modo que todas/os fossem, pelo menos uma vez, a/o última/o da fila para jogar a bola no gol. 
Objetivo: Limitar os movimentos dos membros superiores das/os alunas/os para vivenciarem, de maneira simulada, a deficiência motora.

5ํ- - reaplicação do questionário (pós), agradecimento a/aos alunas/os referente às suas participações e algumas reflexões sobre a importância da inclusão.

\section{RESULTADOS E DISCUSSÃO}

Os dados a seguir referem-se a comparação da frequência das respostas obtidas nos questionários pré e pós intervenção, e a partir dessa análise verificarmos impactos na atitude das/os participantes frente a inclusão de estudantes com deficiência nas aulas de educação física.

As primeiras questões traçaram um rápido perfil das/os participante quanto a gênero, idade e uma questão sobre convivência com pessoas com deficiência, a qual praticamente metade da amostra respondeu que convive ou já conviveu com pessoas com deficiência.

Quando questionadas/os "Se tudo bem para eles ter um colega com deficiência nas aulas de Educação Física", como perceber na figura 1, destaca-se que a maioria optou entre as respostas "sim" e "acho que sim". Entretanto houve uma redução após a intervenção para a resposta "sim".

Figura 1. Resultado das respostas em porcentagem (\%) referente a questão 2.

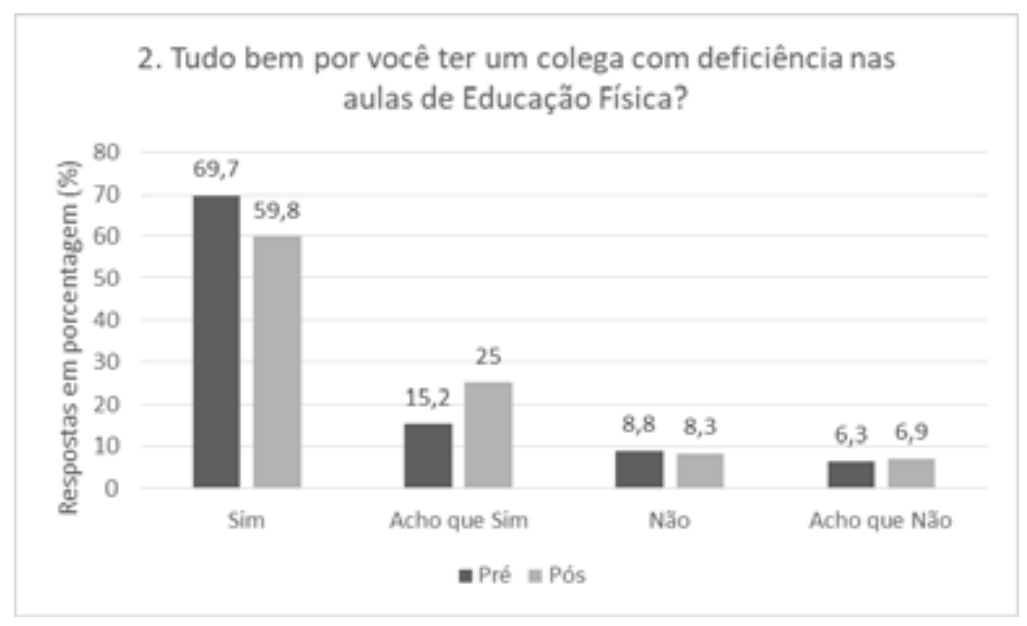

FONTE: As autoras (2018) 
Para entender essa diferença, Gadotti (1998 apud TESSARO et al., 2005) afirma que a educação inclusiva trata-se de um processo que demanda um certo tempo e pode ser complexo, pois envolve um novo paradigma conceitual e ideológico, o qual precisa envolver políticas, programas, serviços sociais, comunidade, entre outras ações. Diferente da opção "sim", a alternativa "acho que sim" apontou um aumento de 9,8\% pós intervenção. Sendo assim, $15,2 \%$ respondeu "sim" e 25\% "acho que sim".

A análise da terceira pergunta (Figura 2), que questiona se o participante se importaria em deixar o jogo mais lento, nos permitiu identificar os seguintes dados: na opção "sim" ocorreu a queda de 10,1\% pós intervenção, na alternativa "acho que sim" houve o aumento de 9,9\% na reaplicação dos questionário. Pré intervenção aproximadamente 70\% das/os participantes responderam que se importariam em deixar o jogo mais lento para que o colega com deficiência participasse.

Figura 2. Resultado das respostas em porcentagem (\%) referente a questão 3.

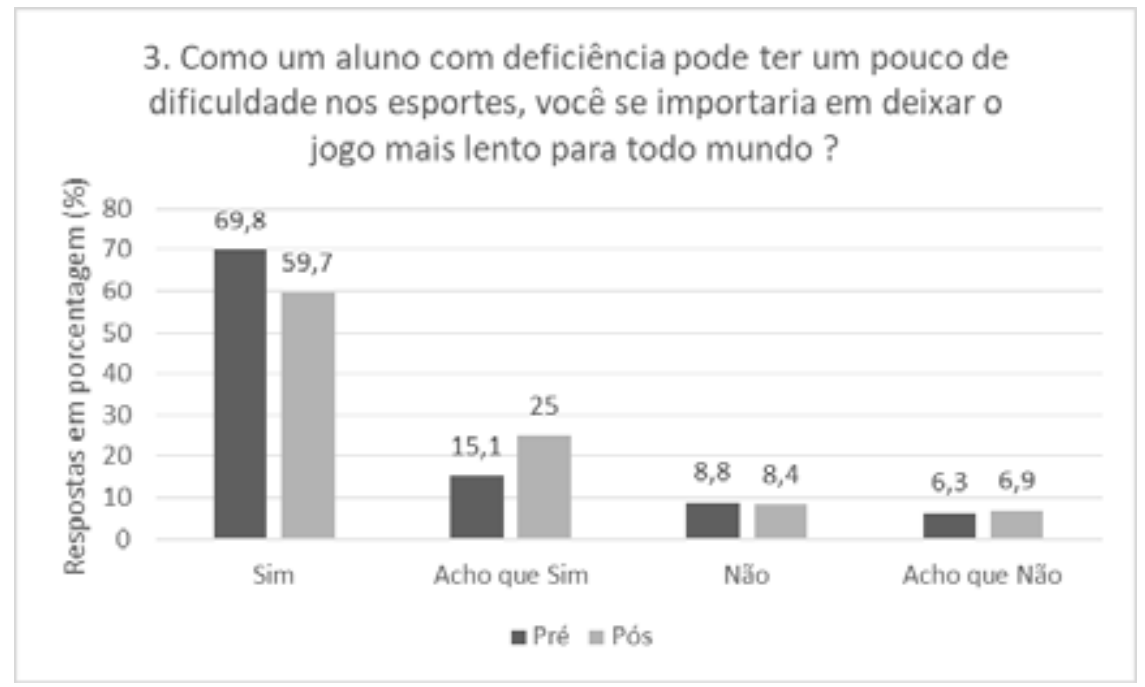

FONTE: As autoras (2018)

Segundo Silva (2006), acredita-se que isso ocorre pelo fato da deficiência causar uma certa estranheza num primeiro contato, que pode manter-se ao longo do tempo a depender do tipo de interação e dos componentes dessa relação. Nota-se que após as atividades inclusivas houve uma mudança 
de opinião, possivelmente o conhecimento adquirido acerca da deficiência, das potencialidades e das restrições que ela provoca, tenha sido o motivo. Tal resultado evidencia a importância do papel do/a educador/a em ampliar sua abordagem e valorizar as diferenças individuais, apresentar conteúdos variados que, não apenas aumente o repertório sensório e perceptivo motor das/os estudantes, mas também contemple as inúmeras possibilidades de ser.

Ao serem questionadas/os se elas/es se importariam em ter um colega com deficiência no seu time na prática de modalidades coletivas, a maioria respondeu não se importar e houve aumento de 10,3\% após intervenção. Aquelas/es que responderam "sim" 11,6\% anterior a intervenção apresentarm diminuição de 4,7\% no período posterior.

Figura 3. Resultado das respostas em porcentagem (\%) referente a questão 4.

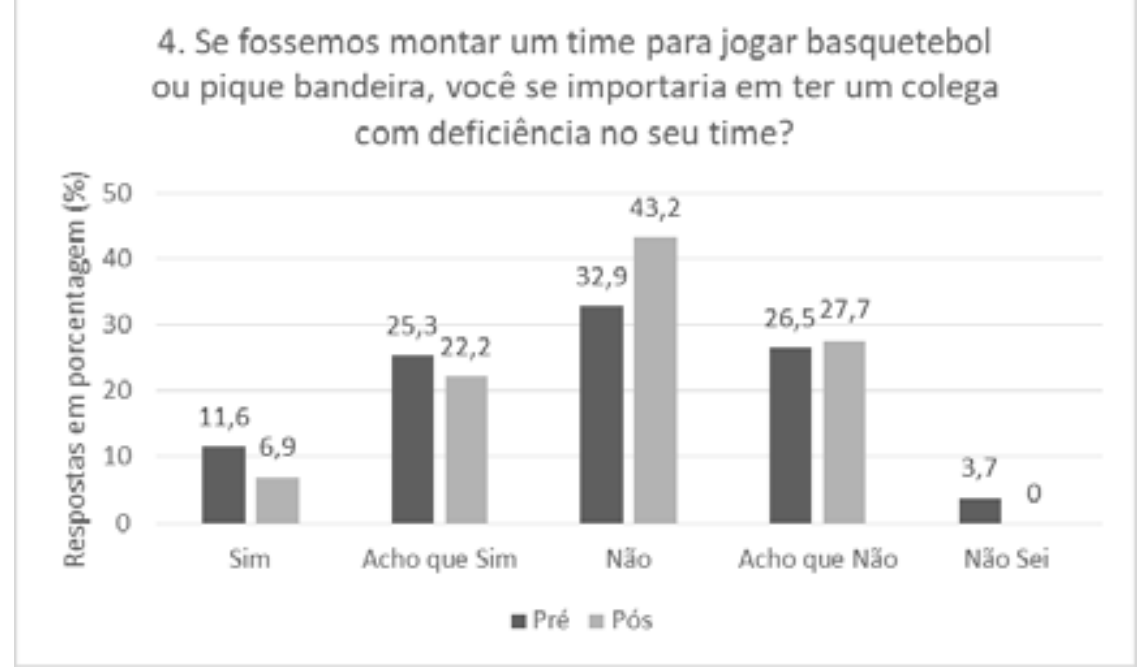

FONTE: As autoras (2018)

De acordo com Farias (2017), praticar a inclusão nas aulas de educação física afasta o preconceito, valoriza a/o aluna/o com necessidades especiais, melhora as relações sociais e cria uma atmosfera participativa em que as aulas realmente são para todas/os. Tal afirmação pode ser comprovada através da opção "não" respondida pelas/os alunas/os, que apresentou um resultado notável após a intervenção. 
Na figura 4 destaca-se a opção "não" na fase pré intervençao com $64,8 \%$, que se refere à aula de Educação Física, se ela seria mais divertida se um aluno com deficiência estivesse participando. Entretanto, os resultados pós intervenção diminuíram 17,6\%, totalizando 47,2\%. Porém, a opção "acho que não" na pós intervenção aumentou 11,3\%, com 27,7\%, enquanto a pré intervenção obteve 16,4\%.

Figura 4. Resultado das respostas em porcentagem (\%) referente a questão 5.

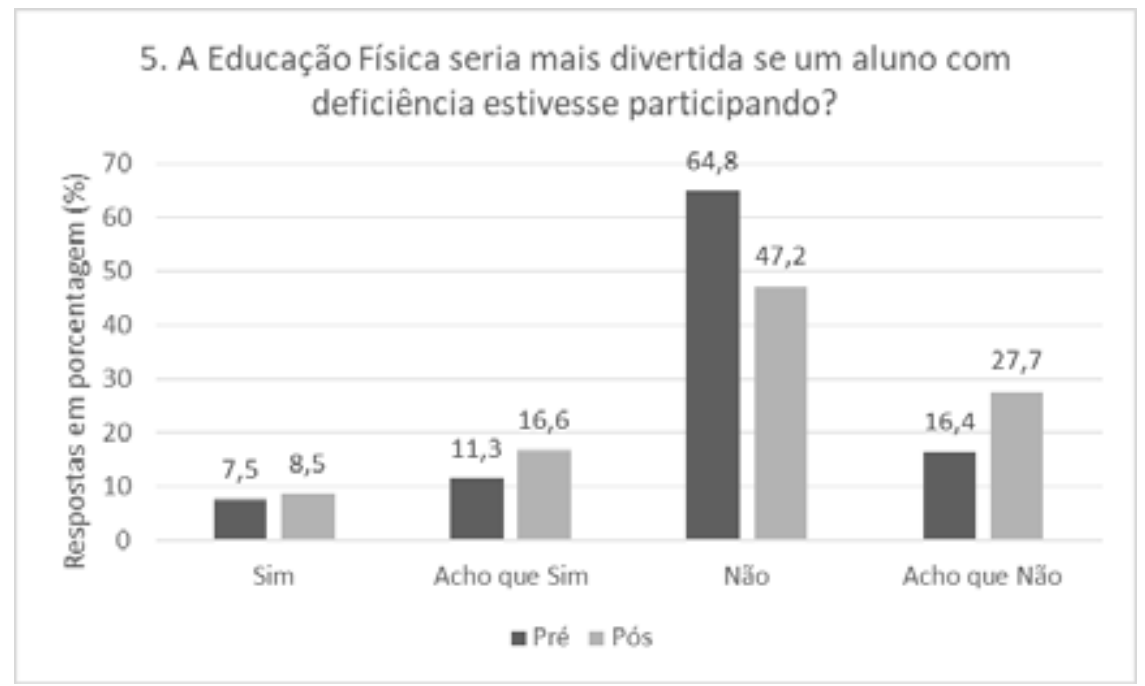

FONTE: As autoras (2018)

É possível que os resultados envolvendo as opções "não" e "acho que não" estejam relacionados a atitudes baseadas no preconceito, que de acordo com Silva (2006) trata-se de um mecanismo de negação social, que ressalta as diferenças como déficit, com falta, como 'menos que', e ainda como impossibilidade. Como se o corpo da pessoa com deficiência não pudesse corresponder as demandas sociais, consideradas como intensas, levando ao desgaste físico e prejuízo para o desenvolvimento dela.

A questão 6, ilustrada na figura 5, buscou compreender se os participantes conversariam e seriam amigos de um/a colega com deficiência na aula de Educação Física. Destaca-se o aumento da resposta "acho que sim" entre pré e pós intervenção de 40,1\% para aproximadamente $60 \%$, salientando que a simulação de situações que passam as pessoas com deficiência é capaz 
de aproximar as/os envolvidas/os no ambiente da educação física inclusiva. Salientamos também a redução nas respostas sim, de 22,7\% para 9,9\% que podem estar vinculadas a compreensão da diferença como algo distante e alvo de separação.

Figura 5. Resultado das respostas em porcentagem (\%) referente a questão 6.

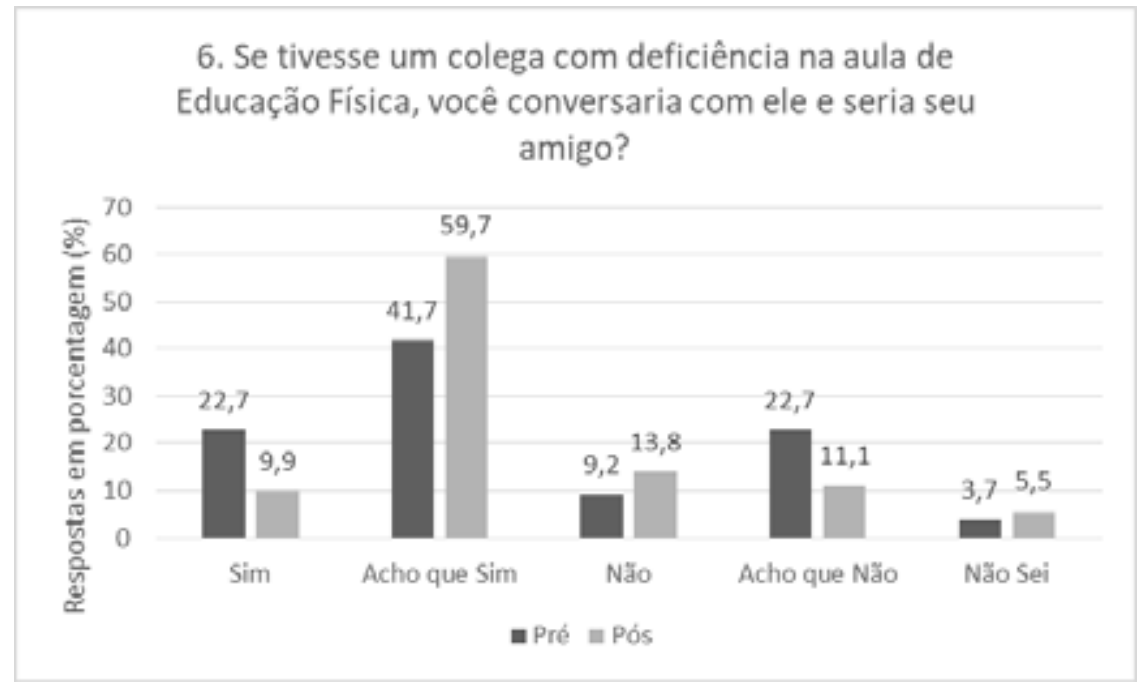

FONTE: As autoras (2018)

Nesse sentido, como descreve Silva (2006), os contatos com pessoas com deficiência podem ser prejudicados pela inabilidade que alguns apresentam de lidar com elas. Essa afirmação merece destaque no sentido de desconstruir tal crença, e as aulas de educação física podem e devem ser ambiente propício para se exercitar a convivência entre pares com e sem deficiências, respeitando as particularidades e jeito de ser de cada uma, cada um.

Na questão que tem como objetivo identificar se os participantes saberiam ajudar um colega com deficiência em alguma atividade nas aulas, ou no dia-a-dia (figura 6), observa-se que a opção "sim" obteve maiores valores na primeira aplicação do questionário, já a questão "acho que sim" apontou os maiores valores na reaplicação. Pode-se dizer que ouve uma migração do pré para o pós da opção "sim" para a opção "acho que sim". 
Figura 6. Resultado das respostas em porcentagem (\%) referente a questão 7.

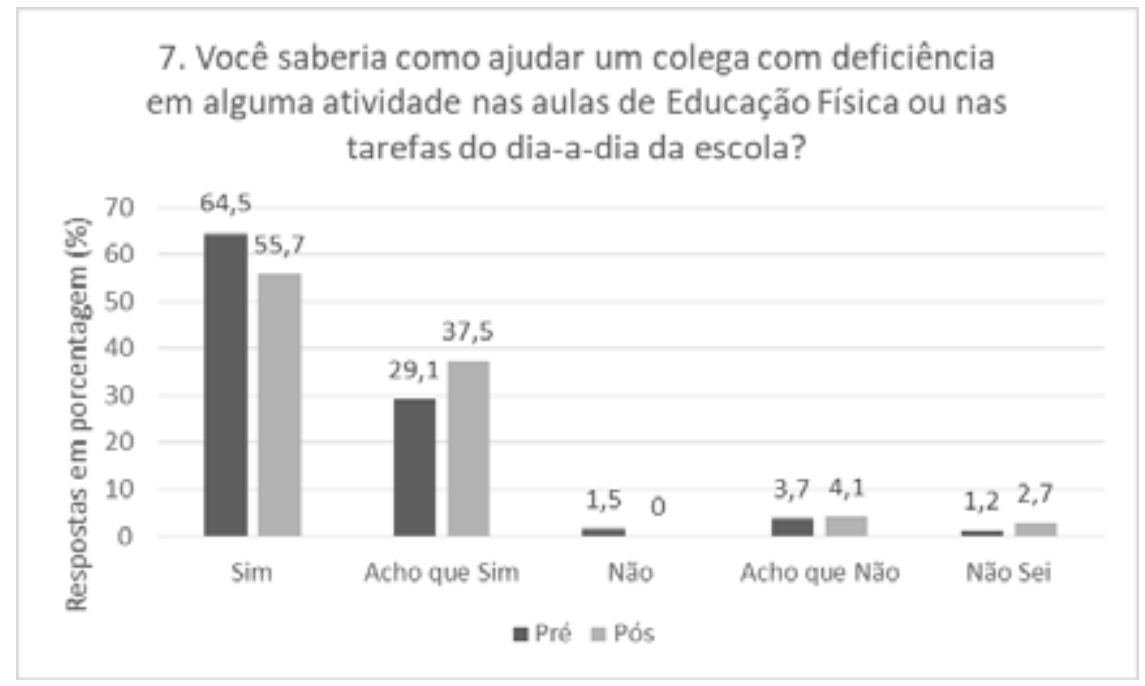

FONTE: As autoras (2018)

A diminuição do "sim" e o aumento do "acho que sim", corrobora com a afirmação de Farias (2017), na qual a autora aponta que a inclusão faz com que as/os alunas/os entendam as dificuldades da/o colega com necessidades especiais, pois sentir na pele o que passam facilita o entendimento das suas potencialidades e suas possíveis limitações.

A questão representada na figura 7 buscou saber se as/os participantes gostariam de ajudar um aluno com deficiência a aprender e a praticar os jogos nas aula de Educação Física, observa-se que as opções "sim" e "acho que sim" obtiveram maiores valores pré intervenção, já as opções "não" e "acho que não" apresentaram maiores valores pós intervenção. 
Figura 7. Resultado das respostas em porcentagem (\%) referente a questão 8.

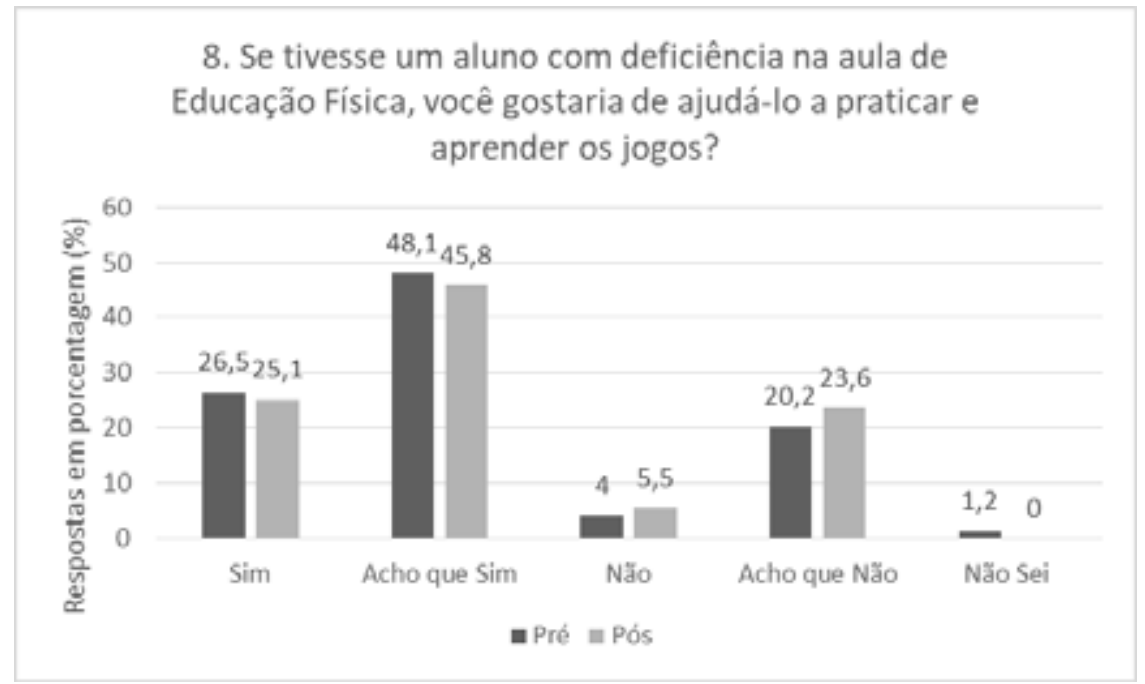

FONTE: As autoras (2018)

Embora as opções "não" e "acho que não" ligeiramente aumentaram, as opções favoráveis à inclusão mantiveram-se com altas porcentagens. É provável que as dificuldades e complexidades vivenciadas na simulação das tarefas tenham determinado as respostas pós intervenção negativas. Auxiliar estudantes com deficiência na aprendizagem de jogos e vivências motoras requer preparo técnico, prática, e evidencia a relevância de treinamento do parceiro tutor na condução dessa ajuda. Como explicitam Fiorini e Nabeiro (2013):

Conscientes da existência, por muitas vezes, de um colega de classe que auxilia o aluno com deficiência de forma natural e espontânea, o treinamento do Colega Tutor é uma estratégia para preparar os alunos neste auxílio, tanto ao aluno com deficiência quanto ao próprio professor de Educação Física. Por meio do treinamento, os alunos podem aprender vários conteúdos, como as características da deficiência e as formas específicas de ajuda. Sendo assim, o Colega Tutor treinado é uma estratégia de ensino que pode ser utilizada para dinamizar a aula de Educação Física no contexto da inclusão educacional e, ainda, diminuir o preconceito, pois apresenta muitas informações importantes para a compreensão das necessidades e das capacidades dos alunos com deficiência (FIORINI; NABEIRO, 2013, p. 17).

A questão apresentada na figura 8 buscou entender se as/os participantes se importariam em mudar as regras do jogo para que um colega com defi- 
ciência participasse. A opção "sim" apresentou 60,9\% na primeira aplicação, já na segunda 56,9\%. A questão "não" aumentou 4,6\% pós intervenção.

Em contradição à figura 7, a questão 9 aponta uma negativa quando se trata de inclusão. Um fator preponderante pode ser o desejo pela competição que normalmente ocorre nas aulas de educação física nesse ambiente investigado.

Figura 8. Resultado das respostas em porcentagem (\%) referente a questão 9.

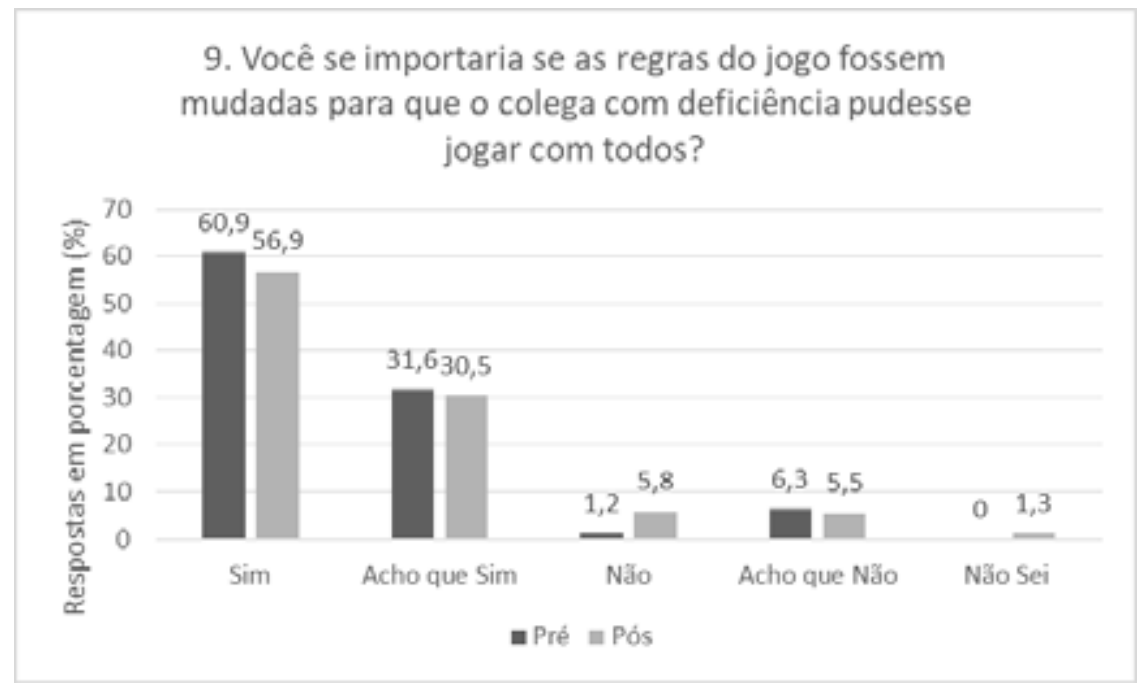

FONTE: As autoras (2018)

Sobre a cultura desportiva e competitiva, Rodrigues (2006) relata que "[...] dominante nas propostas curriculares da educação física, cria um obstáculo adicional à inclusão de alunos que são à partida encarados como menos capazes para um bom desempenho (por variadas razões) numa competição". Assim, a união do paradigma competitivo com o desconhecimento das potencialidades presente na diversidade de corpos promove, a princípio, a negação para a criação de novas possibilidades de prática, advindas das alterações das regras. As práticas já conhecidas e padronizadas de jogos e esportes acabam sendo mais atrativas nesse primeiro momento e a introdução de novas práticas, nesse caso, pode ser feita de forma progressiva. 
Na figura 9 os dado apontam quais foram as atividades inclusivas desenvolvidas com as/os participantes que elas/es mais gostaram. As atividades indicadas como mais atrativas foram as atividades com bola, sendo a bola com guizo uma novidade para eles. Mas de maneira geral, mais de 90\% das/ os participantes aprovou as atividades que, cabe ressaltar, foram desenvolvidas de forma lúdica. Carvalho (2010) salienta a importância de atividades lúdicas para trabalhar valores básicos de convivência humanizadora. Através da ludicidade em grupo é possível exercitar o respeito mútuo, lealdade, não violência, solidariedade, valorização e cuidado da/o e com a/o outra/o.

Figura 9. Resultado das respostas em porcentagem (\%) referente a questão 10.

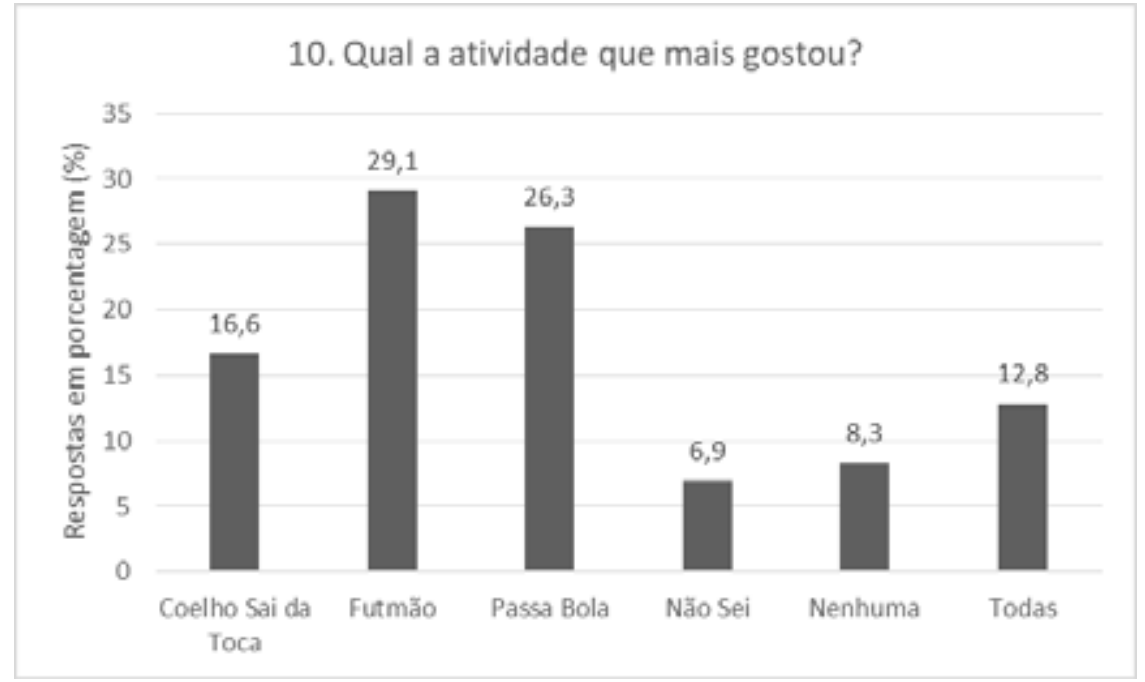

FONTE: As autoras (2018)

O gráfico da figura 10 retrata uma questão aberta, em que os participantes deveriam expressar a sua opinião em uma palavra, em relação à pessoas com deficiência, sendo que alguns relataram mais de uma palavra. Exemplos de palavras positivas (que em muitos casos descreveram frases), foram: "não desista" e "todos tem direitos iguais", e exemplos das negativas foram "decepcionante" e "desanimada". 
Figura 10. Resultado das respostas em porcentagem (\%) referente a questão 12.

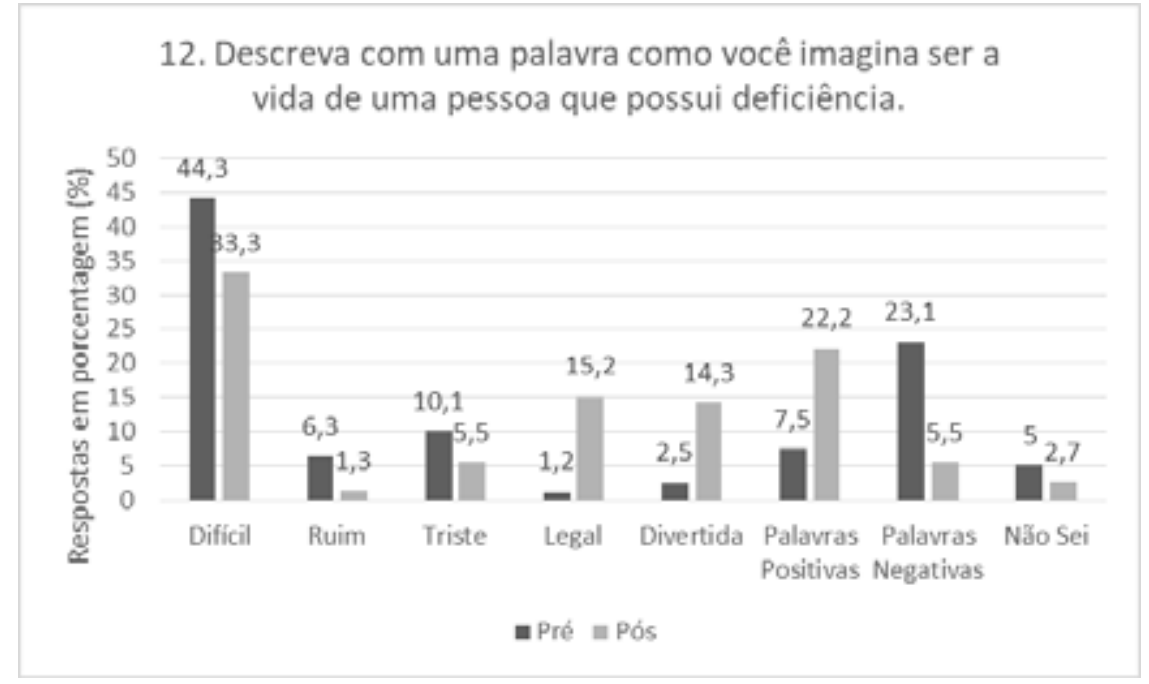

FONTE: As autoras (2018)

Destacam-se as seguintes opções com resultados expressivos: "difícil", "palavras positivas" e "palavras negativas". Na primeira aplicação a palavra "dificil" aparece com "44,3\%, e no pós surge com 33,3\%. As palavras positivas pré e pós apresentam os respectivos valores: 7,5\% e 22,2. As palavra negativas apontam $23,1 \%$ na primeira aplicação e 5,5 na segunda.

A questão 12 pré intervenção evidencia uma visão estereotipada das/os alunas/os sobre a deficiência. Acredita-se que a causa seja a falta de informação ou informação baseada em preconceitos e falsas informações. Ferreira e Bozzo (2009) reforçam que o preconceito é baseado na falta de informação e ainda, que a presença de crianças com deficiência na escola regular naturaliza a convivência entre pares com e sem deficiência. Para as autoras, a educação é responsável por essa mudança de visão dos indivíduos, e uma de suas missões é a de passar informação, que torna-se uma das formas mais simples de se combater o preconceito.

\section{CONSIDERAÇÕES FINAIS}

Através das atividades inclusivas, as/os alunas/os de $5 \underline{a}$ ano do ensino regular puderam vivenciar e explorar não apenas novas tarefas sensório e per- 
ceptivo motoras, mas mais do que isso, experienciaram a execução de tarefas simulando deficiência. Essas tarefas, realizadas de maneira lúdica na aula de educação física, permitiram momentos de reflexão e de exercício da empatia, capazes de impactar conceitos e valores dessas/es participantes do estudo.

Os dados obtidos através dos questionários pré e pós intervenção apontaram impactos tanto positivos, isto é, atitudes em direção à inclusão como não se importar em ter um/a colega com deficiência em sua equipe, quanto negativos, não favoráveis a inclusão como se importar em deixar o jogo mais lento com a presença de um/a aluno com deficiência. Cabe ressaltar que não necessariamente a presença de estudantes com deficiência nos jogos e brincadeiras resultam em maior lentidão e necessidade de alteração nas regras.

Embora tenha sido realizada num curto prazo, a intervenção trouxe mais mudanças positivas que negativas na visão das/os alunas/os participantes sobre a deficiência e a inclusão. No entanto, para um aprofundamento e maior compreensão do tema, se faz necessário um programa de intervenção mais intenso, considerando maior tempo de vivências, apresentação de conhecimentos sobre as características e peculiaridades das deficiências, dar visibilidade da prática de atividade e esportes para pessoas com deficiência, como por exemplo jogos paraolímpicos, visitas em treinamentos ou palestras com atletas do paradesporto, entre outras ações que aproximem pessoas com deficiências com a comunidade escolar.

Se o pretendido é que a escola seja inclusiva, é de suma importância que seus planos sejam reelaborados na direção de uma educação voltada para a cidadania global, plena, livre de preconceitos, que reconheça e valoriza as diferenças. Sendo assim, é preciso educar para a liberdade, tornando-se inaceitável nenhuma forma de subordinação e finalmente, entende-se que para obter sucesso no processo de inclusão é necessário comprometimento e trabalho em conjunto, envolvendo o Estado, a família, a instituição de ensino, o/a professor/a, as/os alunas/os e a sociedade em geral.

\footnotetext{
Resumo: O presente trabalho teve como objetivo avaliar o impacto de um programa de intervenção com vivências de atividades físicas adaptadas, simulando deficiências sensoriais e motora, nas atitudes de alunas/ os sem deficiência sobre o processo de inclusão. Para tanto, 79 estudantes com idade variando entre 9 e 11 anos, de turmas de $5 \mathbf{0}$ ano de um colégio de ensino privado da cidade de Curitiba/PR participaram da pesquisa que consistiu da aplicação de questionários pré e pós período de intervenção caracterizado pela vivência de atividades motoras adaptadas, simulando as deficiências visual, auditiva e motora ("Futmão", "Coelho
} 
sai da toca" e "Passa a bola"). Os dados obtidos apontaram que, para a maioria das variáveis investigadas, houve impacto positivo em direção à inclusão, porém algumas respostas indicaram um direcionamento não favoráveis, como por exemplo, se importar em deixar o jogo mais lento com a presença de um/a aluno com deficiência. Ressaltamos que intervenção pedagógica utilizando práticas lúdicas de atividade física que simulam a restrição sensorial e motora, pode contribuir para o desenvolvimento da empatia e assim despertar e manter um ambiente escolar favorável à inclusão.

Palavras-chave: Educação Física. Inclusão. Atitude.

\begin{abstract}
The present study aimed to evaluate the impact of an intervention program with adapted physical activity experiences, simulating sensory and motor deficiencies, in the attitudes of students without disabilities on the inclusion process. For this purpose, 79 students aged between 9 and 11 years old, from 5th grade classes at a private school in the city of Curitiba / PR participated in the research that consisted of the application of questionnaires before and after the intervention period characterized by the experience of adapted motor activities, simulating visual, auditory and motor deficiencies ("Futmão", "Bunny out of the hole" and "Pass the ball"). The data obtained showed that, for most of the variables investigated, there was a positive impact towards inclusion, but some responses indicated an unfavorable direction, such as, for example, caring about slowing down the game with the presence of a student. with disabilities. We emphasize that pedagogical intervention using playful physical activity practices that simulate sensory and motor restriction, can contribute to the development of empathy and thus awaken and maintain a school environment favorable to inclusion.
\end{abstract}

Keywords: Physical Education. Inclusion. Attitude.

\title{
REFERÊNCIAS
}

ARAÚJO, P. F. Desporto adaptado no Brasil. São Paulo: Phorte, 2011.

AWAD, H. Educação física escolar: múltiplos caminhos. São Paulo: Fontoura, 2010.

FERREIRA, M. M.; BOZZO, F. E. Inclusão de crianças com Síndrome de Down no ciclo I do ensino fundamental. In: SIMPÓSIO DE EDUCAÇÃO UNISALESIANO, 3., 2009, Lins. Anais [...]. Lins: Unisalesiano, 2009. Disponível em: http://www.unisalesiano.edu.br/encontro2009/trabaIhosaceitos.php. Acesso em: 12 nov. 2018.

FERREIRA, V. Educação física adaptada: atividades especiais. Rio de Janeiro: Sprint, 2010.

FIORINI, M. L. S.; NABEIRO, M. Treinamento de colegas tutores como auxílio à inclusão de alunos com deficiência em aulas de educação física. Revista Adapta, Presidente Prudente, v. 9, n. 1, p. 13-18, 2013.

FREITAS, S. N. A formação de professores na educação inclusiva. In: RODRIGUES, David (Org.). Inclusão e educação: doze olhares sobre a educação inclusiva. São Paulo: Summus, 2006.

HEHIR, T.; PASCUCCI, S. Os benefícios da educação inclusiva para estudantes com e sem deficiência. São Paulo: Instituto Alana, Abt Associates, 2016.

MANTOAN, M. T. O direito de ser, sendo diferente, na escola. In: RODRIGUES, David (Org.). Inclusão e educação: doze olhares sobre a educação inclusiva. São Paulo: Summus, 2006.

MAUERBERG-DECASTRO, E. Atividade física adaptada. 2. ed. São Paulo: Novo Conceito, 2011.

MAUERBERG-DECASTRO, E.; CASTRO, R. M. Atividade física adaptada na escola inclusiva. In: MAUERBERG-DECASTRO, E. Atividade física adaptada. 2. ed. São Paulo: Novo Conceito, 2011.

RODRIGUES, D. Inclusão e educação: Doze olhares sobre a educação inclusiva. São Paulo: Summus, 2006. 
SALAMANCA. Declaração de Salamanca (1994). Disponível em: http://portal.mec.gov.br/seesp/ arquivos/pdf/salamanca.pdf. Acesso em: 10 mai. 2018.

SILVA, L. M. O estranhamento causado pela deficiência: preconceito e experiência. Revista Brasileira de Educação, Rio de Janeiro, 11, 33, set./dez. 2006.

TESSARO, N. S. Inclusão escolar: concepções de professores e alunos da educação regular e especial. São Paulo: Casa do Psicólogo, 2005.

Recebido em Novembro de 2020

Aprovado em Abril de 2021 